\title{
ARTIGOS
}

\section{ANÁLISE DA MULTIDIMENSIONALIDADE DOS CONCEITOS DE BACIA HIDROGRÁFICA}

\author{
Raul Carneiro Gomes ${ }^{1}$ \\ Universidade Federal do Ceará \\ Christina Bianchi \\ Universidade Federal do Ceará
}

Vládia Pinto Vidal de Oliveira ${ }^{3}$

Universidade Federal do Ceará

Enviado em 20 jan. 2019 | Aceito em 31 mar. 2021

Resumo: A bacia hidrográfica (BH) é um objeto de estudo utilizado pela Geografia e pelas Ciências Ambientais, por isso novas definiçõ es foram criadas, compatibilizando essa célula de análise espacial e de planejamento com os estudos integrados. Assim, é importante averiguar se os conceitos criados sofreram adaptações e delimitações apropriadas para descreverem o objeto que definem e serem aplicados aos estudos tecnocientíficos. Nessa perspectiva, parte-se da hipótese de que os conceitos de BH, sub-bacia e microbacia hidrográficas foram adaptados, mas apresentam imprecisões nas suas delimitações conceituais. Portanto, objetivou-se identificar e analisar os conceitos mais citados na literatura, almejando aperfeiçoá-los. Para tanto, executou-se uma pesquisa bibliográfica na qual foram identificados e examinados os principais conceitos de $\mathrm{BH}$, sub-bacia e microbacia hidrográfica utilizados atualmente. Posteriormente, buscaram-se características particulares de cada categoria de uma BH para distinguir as definições estudadas, bem como propor requalificações. Logo, verificou-se que os conceitos disponíveis na literatura sofreram adaptações, porém frequentemente reduzem uma $\mathrm{BH}$ e suas categorias hierárquicas aos seus aspectos hidrológicos ou espaciais. O sistema de hierarquização de BH e as definições analisadas apresentam falhas no ordenamento e nas delimitações conceituais de seus objetos, assim foi possível propor aprimoramentos nas definições estudadas.

Palavras-chave: Hidrologia; Sistema Ambiental; Unidade de Planejamento.

\section{ANALYSIS OF MULTIDIMENSIONALITY OF HYDROGRAPHIC BASIN CONCEPTS}

Abstract: The hydrographic basin (HB) is a study object used for Geography and Environmental Sciences, therefore new definitions have been created, making this cell of spatial analysis and planning compatible with integrated studies. Thus, it is important to ascertain whether the concepts created have undergone appropriate adaptations and delimitations to describe the object that they define and apply to technoscientific studies. In this perspective, it is based on the hypothesis that the concepts of HB, hydrographic sub-basin and microbasin have been adapted, but they present naccuracies in their conceptual delimitations. Therefore, the objective was to identify and analyze the most cited concepts in literature, aiming to improve them. For this, bibliographical research was carried out in which the main concepts of HB, sub-basin and microbasin used today were identified and examined. Subsequently, particular characteristics of each category of a HB were sought to distinguish the definitions studied, as well as to propose requalifications. Therefore, it was verified that the concepts available in literature have undergone adaptations, but often reduce a HB and its hierarchical categories to its hydrological or spatial aspects. The

1. Doutor em Geografia pela Universidade Federal do Ceará. E-mail: raulcarneiro89@hotmail.com. ORCID: https://orcid.org/0000-0002-0651-477X

2. Pós-doutoranda em Desenvolvimento e Meio Ambiente pela Universidade Federal do Ceará. Doutora em Engenharia do Ambiente-FEUPO. E-mail: bianchi.cb@gmail.com. ORCID: https://orcid.org/0000-0003-0333-4797

3. Doutora em Engenharia Agronômica-UAL. Professora do departamento de Geografia da Universidade Federal do Ceará. E-mail: vladia.ufc@gmail.com. ORCID: https://orcid.org/0000-0001-7756-9009 
hierarchical system of HB and the analyzed definitions present faults in the ordering and conceptual delimitations of its objects, so it was possible to propose improvements in the definitions studied.

Keywords: Hydrology; Environment System; Planning Unit.

\section{ANÁLISIS DE LA MULTIDIMENSIONALIDAD DE LOS CONCEPTOS DE CUENCA HIDROGRÁFICA}

Resumen: La cuenca hidrográfica (BH) es un objeto de estudio utilizado por la Geografía y las Ciencias Ambientales, por eso nuevos conceptos han sido propuestos, compatibilizando el análisis espacial y de planificación con los estudios integrados. Así, es importante averiguar si los conceptos creados han sufrido adaptaciones y delimitaciones apropiadas para describir el objeto que definen y ser aplicados a los estudios tecnocientíficos. En esta perspectiva, se parte de la hipótesis de que los conceptos de $\mathrm{CH}$, subcuenca y microcuenca han sido adaptados, pero presentan imprecisiones en sus delimitaciones conceptuales. Por lo tanto, se objetivó identificar y analizar los conceptos más citados, anhelando perfeccionarlos. Para ello, se ejecutó una investigación bibliográfica en la que se identificaron y examinaron los principales conceptos de $\mathrm{CH}$, subcuenca y microcuenca hidrográfica utilizados actualmente. Posteriormente, se buscaron características particulares de cada categoría de una $\mathrm{CH}$ para distinguir las definiciones estudiadas, así como proponer recalificaciones. Luego, se verificó que los conceptos disponibles en la literatura sufrieron adaptaciones, pero frecuentemente reducen una $\mathrm{CH}$ y sus categorías jerárquicas a sus aspectos hidrológicos o espaciales. El sistema de jerarquización de $\mathrm{CH}$ y las definiciones analizadas presentan fallas en el ordenamiento y en las delimitaciones conceptuales de sus objetos, así fue posible proponer mejoras en las definiciones estudiadas.

Palabras-clave: Hidrología; Sistema Ambiental; Unidad de Planificación.

Introdução

Em meio à crise ambiental que a sociedade contemporânea tem sofrido, a busca pela compreensão das características e do funcionamento dos sistemas ambientais destaca-se, para o aperfeiçoamento do manejo das atividades sociais e para mitigar os impactos ambientais negativos decorrentes de tais atividades sobre o espaço. Entretanto, dada a complexidade dos ambientes, a realização de estudos holísticos não é simples, tendo em vista que nem todos os elementos socioambientais e suas inter-relações são plenamente conhecidos.

Anteriormente, os recursos naturais eram estudados sem conexão com o seu meio. Tal abordagem reducionista foi eficiente na análise vertical dos seus objetos, mas negligenciava as variáveis horizontais relacionadas a estes, isto é, compreendia-se muito sobre um determinado recurso natural, mas não havia a preocupação em entender as inter-relações deste com os demais, tampouco as propriedades emergentes oriundas dessas interações.

Visando à superação do quadro anterior, a bacia hidrográfica $(\mathrm{BH})$ tem sido uma célula ou categoria de análise empregada nas análises socioambientais por ser um sistema ambiental e uma unidade de planejamento cujos elementos, estruturas e processos podem ser modelados e estudados integradamente (CHRISTOFOLETTI, 1999; FAO, 2018; GASPARI et al., 2013). Nesse contexto, acredita-se que a BH tem assumido diversas denotações que têm ampliado sua designação e permitido sua utilização para além dos seus aspectos hidrológicos.

Assim, embora a categoria posta seja vastamente utilizada, sua qualificação ainda é passível de reflexões conceituais e aprimoramentos para maximizar seu significado e sua precisão, sobretudo no que tange aos conceitos de sub-bacia e microbacia hidrográficas, que são empregados indiscriminadamente. Estes são expressivamente usados nos trabalhos acadêmicos e técnicos, contudo apresentam imprecisões qualitativas (conceitos monodimensionais e uso de atributos semelhantes em outras categorias, por exemplo) e quantitativas (ausência de um consenso sobre o 
tamanho de suas áreas, uso de ordens de drenagens presentes nas duas categorias de $\mathrm{BH}$ etc.) que causam uma insegurança conceitual, dificultando o entendimento universal do objeto descrito.

Diante da relevância da célula exposta e de sua conceituação, este trabalho parte da hipótese de que o conceito de $\mathrm{BH}$ foi aperfeiçoado e adaptado ao longo do tempo e suas subcategorias hierárquicas (sub-bacia e microbacias) não têm características qualitativas e quantitativas fixas presentemente. Deste modo, objetivou-se realizar uma análise da literatura sobre a temática, buscando variações das conceituações postas, a fim de substanciar a proposição de definições coerentes com a realidade multidimensional abrangida por uma $\mathrm{BH}$.

Em consonância com isso, a construção deste trabalho pautou-se na realização de um levantamento bibliográfico que contemplou também a consulta aos relatórios técnicos e artigos científicos presentes na rede mundial de computadores (internet) e na análise integrada das informações obtidas, que são demonstradas nas seções posteriormente. Com isso, são apresentados os conceitos de $\mathrm{BH}$ e suas categorias hierárquicas presentes nos trabalhos tecnocientíficos consultados. Em seguida, são discutidas as denominações encontradas e propostas novas conceituações relativas geradas a partir das características comuns presentes nos conceitos examinados.

\section{Bacia hidrográfica: conceitos de uma célula de análise}

Muitos são os trabalhos científicos internacionais (STRAHLER, 1957, 1979; PUMO et al., 2014; NAQVI et al., 2015; THORNBRUGH et al., 2018), nacionais (CHRISTOFOLETTI, 1979, 1980, 1981; SOUZA; PEREZ FILHO, 2016; ANA, 2018), nordestinos (CUNHA et al., 2012; MAIA; BEZERRA, 2011; MARTINS, 2013) e cearenses (ARAÚJO, 2003; MAIA, 2006; SOUZA; SANTOS; OLIVEIRA, 2012; QUEIROZ et al., 2018). Eles têm utilizado a BH como célula de análise e/ou como sistema que comporta determinado(s) subsistema(s) alvo(s) de estudo.

Todos esses trabalhos têm contribuído distintamente para a compreensão dos atributos de uma $\mathrm{BH}$, tais como o entendimento da morfometria de seus cursos fluviais via sensoriamento remoto ou não, a análise dos relevos presentes em uma $\mathrm{BH}$, a avaliação dos hidrossedimentos, a apreensão da qualidade e a quantidade hídrica, a aplicação da análise ambiental sistêmica, a realização do diagnóstico ambiental e dos hidroterritórios. Diante disso, compreende-se que a BH é uma célula de análise utilizada desde a dimensão internacional à estadual para examinar diversos objetos amostrais.

Com base na revisão da literatura, observou-se que a BH está consolidada como uma célula de análise espacial para os estudos que versam desde os aspectos físico-naturais aos culturais das paisagens terrestres. Em virtude da sua multidimensionalidade e complexidade, verifica-se, no quadro 1 , que a $\mathrm{BH}$ possui diversos significados e características que estão atreladas às abordagens e aos contextos pesquisados.

Deste modo, os conceitos presentes no quadro 1 podem ser agrupados em perspectivas específicas, como a hidrológica, a geomorfológica, a de gestão e o planejamento espacial, que, por sua vez, aglutinam outras correntes de pensamento. 


\section{Quadro 1 - Principais conceituações de bacia hidrográfica $(\mathrm{BH})$}

\begin{tabular}{|c|c|}
\hline Autor(es) & Conceitos e características de uma $\mathrm{BH}$ \\
\hline Horton (1945) & $\begin{array}{l}\text { Entende a BH como um sistema composto por um conjunto de canais que } \\
\text { drenam uma determinada superfície terrestre com limites naturalmente } \\
\text { definidos. Entende que os canais fluviais podem ser hierarquizados e } \\
\text { quantificados para fins de compreensão do ciclo hidrológico, da erosão e } \\
\text { da dinâmica natural da bacia. }\end{array}$ \\
\hline Chorley (1962) & $\begin{array}{l}\text { BH é um sistema aberto de captação de água, composto por setores mais } \\
\text { elevados, divisores topográficos, donde partem os cursos de água para } \\
\text { um rio principal rumo a uma saída comum. Deste modo, é um sistema } \\
\text { aberto devido aos seus elementos estarem inter-relacionados por meio de } \\
\text { diversos processos interacionais (hídricos, morfogenéticos, pedogenéticos } \\
\text { e outros) que são desencadeados em função da matéria e energia que } \\
\text { entram no sistema e em seus subsistemas e sai deles. }\end{array}$ \\
\hline Strahler (1979) & $\begin{array}{c}\text { Entende a BH como um sistema de drenagem composto por um conjunto } \\
\text { de pequenas bacias ajustadas em formas e tamanhos em relação ao rio } \\
\text { para o qual confluem. Além disso, entende a } \mathrm{BH} \text { como um sistema hídrico } \\
\text { aberto e dinâmico. }\end{array}$ \\
\hline Christofoletti (1980) & $\begin{array}{l}\text { Compreende a bacia de drenagem como uma área drenada por um rio ou } \\
\text { por um sistema fluvial. Contudo, também inclui a BH como um sistema } \\
\text { dinâmico aberto, passível de ser hierarquizado, delimitado naturalmente } \\
\text { pelos divisores de água e produto de inúmeras inter-relações processuais } \\
\text { de energia, matéria e informações. }\end{array}$ \\
\hline $\begin{array}{c}\text { Sanjaume e Villanueva } \\
(1996)\end{array}$ & $\begin{array}{l}\text { A BH ou cuenca hidrográfica é um sistema que contém um conjunto de } \\
\text { águas que drenam uma área para um mesmo ponto, compondo uma } \\
\text { unidade hidrológica e geográfica definida. Em qualquer setor de um curso } \\
\text { fluvial, é possível traçar uma BH que constitui a sua alimentação até } \\
\text { chegar à área máxima de convergência das águas, porém acrescentam } \\
\text { que, mesmo que a BH tenha limites definidos pelos seus divisores de } \\
\text { água, isso não impede que parte dos aportes hídricos saia do sistema por } \\
\text { falhas e fraturamentos geológicos subterrâneos para as BH vizinhas sem } \\
\text { passarem pelo exutório. }\end{array}$ \\
\hline Brasil (1997) & $\begin{array}{c}\text { Dispõe no artigo } 1^{\circ} \text {, inciso 5, que a BH é a unidade territorial para a } \\
\text { implementação da Política Nacional de Recursos Hídricos e a atuação do } \\
\text { Sistema Nacional de Gerenciamento de Recursos Hídricos. }\end{array}$ \\
\hline Suguio (1998) & $\begin{array}{c}\text { Entende a BH como sinônimo de bacia de drenagem, é uma parte da } \\
\text { superfície terrestre que é ocupada por um sistema de drenagem ou que } \\
\text { colabora com água superficial para o sistema citado. }\end{array}$ \\
\hline $\begin{array}{l}\text { Vélez, Núñez e Trujano } \\
\text { (2003) }\end{array}$ & $\begin{array}{c}\text { A BH é um território, região ou zona cuja característica é que a água pluvial } \\
\text { cai nessa superfície e escorre para um rio comum, isto é, toda a água } \\
\text { acumulada desemboca em um afluente maior, em um lago ou mar. Além } \\
\text { disso, a BH tem uma área superior a } 50.000 \text { ha. }\end{array}$ \\
\hline Botelho e Silva (2004) & $\begin{array}{l}\text { A BH é reconhecida como uma célula básica de análise ambiental, pois } \\
\text { permite avaliar diversos componentes, processos e interações que nela } \\
\text { ocorrem. Ademais, é entendida como um sistema e uma unidade de } \\
\text { planejamento. }\end{array}$ \\
\hline Santos (2004) & $\begin{array}{c}\text { É a circunscrição de um território drenado por um rio principal, seus } \\
\text { afluentes e subafluentes permanentes e intermitentes. Assim, tal conceito } \\
\text { está associado à noção de sistema, de nascentes, de divisores de águas, } \\
\text { de cursos hierarquizados e foz. }\end{array}$ \\
\hline Cunha (2007) & $\begin{array}{l}\text { Conceitua a BH como um espaço drenado por um conjunto de canais } \\
\text { fluviais interligados, que drenam água para um ponto comum. }\end{array}$ \\
\hline Torres e Vianna (2008) & $\begin{array}{c}\text { Propõem o conceito de hidroterritórios que é entendido como uma porção } \\
\text { do espaço dotado de recursos hídricos politicamente administrados pela } \\
\text { gestão pública por meio de normatizações, gestão, controle, } \\
\text { planejamento, cobranças de impostos e pelas relações de pertencimento } \\
\text { e identidade que dadas populações têm com aquela área. Assim, este } \\
\text { conceito abrange não só as relações de poder, mas também as relações } \\
\text { simbólicas e culturais daqueles que habitam o hidroterritório. Este pode } \\
\text { ser uma BH ou uma parcela menor desta, a qual não necessariamente é } \\
\text { uma bacia. }\end{array}$ \\
\hline Guerra e Guerra (2008) & $\begin{array}{l}\text { Entendem que área de drenagem, bacia de drenagem, bacia fluvial e BH } \\
\text { são sinônimos. Definem uma bacia hidrográfica como um conjunto de }\end{array}$ \\
\hline
\end{tabular}




\begin{tabular}{|c|c|}
\hline & $\begin{array}{l}\text { terras drenadas por um rio principal e seus afluentes que são depressões } \\
\text { longitudinais que concentram as águas do escoamento superficial. } \\
\text { Destacam que uma bacia de drenagem é passível de hierarquização dos } \\
\text { cursos fluviais e é dotada de dinamismo, dadas as transformações por } \\
\text { que a BH passa devido à erosão e a outros processos morfogenéticos. }\end{array}$ \\
\hline Novo (2008) & $\begin{array}{c}\text { Conceitua BH como uma área da superfície terrestre drenada por um rio } \\
\text { principal e seus tributários, por isso corresponde a uma área de captação } \\
\text { natural da precipitação, fazendo-a convergir para um único ponto de saída. } \\
\text { A autora também frisa que a bacia é delimitada por divisores de água, os } \\
\text { quais são delimitados via uma carta topográfica ou imagem } \\
\text { tridimensional do terreno. }\end{array}$ \\
\hline Tundisi (2008) & $\begin{array}{c}\text { Área da superfície terrestre drenada por rios e riachos, a BH tem todos os } \\
\text { elementos para a integração de processos biogeofísicos, econômicos e } \\
\text { sociais. Além disso, é uma unidade natural que permite a integração } \\
\text { institucional e a articulação da pesquisa com o gerenciamento, bem como } \\
\text { possibilita a implantação de um banco de dados que funcionará como } \\
\text { uma plataforma para o desenvolvimento de projetos com alternativas, } \\
\text { levando-se em conta os custos destas. }\end{array}$ \\
\hline $\begin{array}{c}\text { Coelho Netto (2009, p.97- } \\
98)\end{array}$ & $\begin{array}{c}\text { "A bacia de drenagem é uma área da superfície terrestre que drena água, } \\
\text { sedimentos e materiais dissolvidos para uma saída comum, num } \\
\text { determinado ponto de um canal fluvial. [...] A bacia de drenagem pode } \\
\text { desenvolver-se em diferentes tamanhos, que variam desde a bacia do rio } \\
\text { Amazonas até bacias com metros quadrados que drenam para a cabeça } \\
\text { de um pequeno canal erosivo ou, simplesmente, para o eixo de um fundo } \\
\text { de vale não canalizado". }\end{array}$ \\
\hline Melo (2009) & $\begin{array}{l}\text { A BH ou de drenagem é uma área da superfície terrestre que drena água, } \\
\text { sedimentos e materiais dissolvidos para o exutório. Tal autor frisa que os } \\
\text { limites da BH são os divisores de água ou topográficos. }\end{array}$ \\
\hline Karmann (2009) & $\begin{array}{l}\text { A BH é conceituada como uma área de captação de água da precipitação, } \\
\text { delimitada por divisores topográficos, onde toda água converge para uma } \\
\text { saída comum, exutório. Com base nisso, esta é um sistema físico, passível } \\
\text { de quantificação do ciclo hidrológico. }\end{array}$ \\
\hline Wani e Garg (2009) & $\begin{array}{l}\text { A BH não é simplesmente uma unidade hidrológica, ela também é uma } \\
\text { entidade social, política e ecológica crucial para a determinação de } \\
\text { alimentos, do quadro social, da segurança econômica que oferece } \\
\text { serviços de suporte para as pessoas do campo. }\end{array}$ \\
\hline Gálvez (2011) & Sistema integrado por várias sub-bacias e microbacias. \\
\hline Gaspari et al. (2013) & $\begin{array}{c}\text { Partindo de um conceito integrador, compreendem a BH como um } \\
\text { sistema de relações sociais e econômicas cuja base territorial e ambiental } \\
\text { é uma rede de drenagem superficial, compostas por rios que confluem } \\
\text { para um rio principal, e este, para o mar. }\end{array}$ \\
\hline
\end{tabular}

A abordagem hidrológica pode ser vislumbrada principalmente nos trabalhos de Horton (1945), Strahler (1979), Suguio (1998), Novo (2008) e Coelho Netto (2009). Afinal, os conceitos adotados por esses autores limitam a $\mathrm{BH}$ a uma área delimitada por interflúvios onde há a drenagem e a convergência hídrica para uma saída comum, chamada de exutório. Essa foi a primeira conceituação atribuída à $\mathrm{BH}$, pois sua complexidade não era plenamente conhecida, assim foi reduzida a um espaço cuja água e seu ciclo eram as variáveis mais importantes.

Essa conceituação ainda é vastamente empregada nos trabalhos acadêmicos e técnicos, embora tenha sido questionada devido a sua conotação naturalista e por restringir a $\mathrm{BH}$ ao âmbito hidrológico, isto é, por não dar ênfase aos seus outros elementos e aos seus processos interativos. Tal situação pode estar relacionada ao fato de o conceito posto ter sido criado operacionalmente para o desenvolvimento e gerenciamento dos recusos hídricos e, apesar de suas limitações, ter sido adotado pelos planejadores e engenheiros em sua unidade para dominar a natureza e "otimizar" 
múltiplas tarefas atribuídas à água e aos benefícios advindos desta (MOLLE, 2009). Portanto, o foco eram os aspectos hídricos, e os demais elementos raramente eram considerados.

Geomorfologicamente, a BH passou a ser compreendida como um sistema aberto e dinâmico, geossistema ou unidade de paisagem. Com isso, há um incremento na abordagem hidrológica, e os estudos passaram a analisar as relações entre os elementos deste sistema (rochas ou sedimentos, clima, geomorfologia, hidrologia, vegetação, solo e outros), contudo as variáveis sociais não eram, significativamente, enfatizadas. Exemplos de conceitos dessa corrente de pensamentos são apresentados por Chorley (1962), Christofoletti (1980), Sanjaume e Villanueva (1996), Cunha (2007), Guerra e Guerra (2008), Karmann (2009) e outros listados no quadro 1.

No âmbito da gestão e do planejamento, Molle (2009) informa que a conceituação de BH tem passado por vários estágios e está em um estado de fluxo. Acrescenta também que, mesmo após sua "descoberta" ocidental no século XVIII, como conceito primordial para a política hídrica europeia, a definição de bacia foi alterada em contextos com evoluções e diferentes intenções (MOLLE, 2009).

Desta maneira, a definição de $\mathrm{BH}$ incorpora as variáveis sociais, políticas, econômicas e culturais, como podem ser vistas em Brasil (1997), Botelho e Silva (2004), Santos (2004), Torres e Vianna (2008), Tundisi (2008), Wani e Garg (2009) e Gaspari et al. (2013). Esse fato ocorreu porque o paradigma analítico tem sido alterado pelo holístico, e isso tem mudado a visão de mundo dos pesquisadores que prezam pela integração. Isso está presente na perspectiva de Gaspari et al. (2013), que dizem que a natureza é uma unidade indivisível, onde os elementos naturais (solo, água, vegetação, fauna, clima e o homem) encontram-se intimamente relacionados e afetam, direta ou indiretamente, a natureza.

Portanto, gradualmente, a $\mathrm{BH}$, que era qualificada basicamente por seus atributos físiconaturais, vai se tornando uma célula de análise mais complexa, porque seu conceito agrega novos valores, expandindo seus limites e suas aplicações além das ciências naturais, portanto sendo empregada também pelas ciências humanísticas.

Sabe-se a definição analisada teve sua aplicação formal como unidade de planejamento, incialmente, nos Estados Unidos, com a criação do Tennessee Valley Authority (TVA) em 1933; posteriormente foi adotada pelo Reino Unido, França, Nigéria e por outros países, como o Brasil em 1980 (BOTELHO, 2009). Deste modo, esta abordagem é a mais empregada nos trabalhos desenvolvidos atualmente, em face da necessidade do planejamento e da gestão para a mitigação da degradação ambiental e para o fomento do ordenamento territorial.

Presentemente, tem-se buscado aprimorar o conceito de BH por meio da proposição de novos qualitativos fisiográficos e sociais, visto que os aspectos quantitativos de uma $\mathrm{BH}$ variam significativamente conforme os âmbitos examinados, por isso, nos conceitos apresentados no quadro 1, não se observa a preocupação em dimensionar numericamente a $\mathrm{BH}$.

Além disso, detectou-se que há uma tendência de o conceito em apreço incorporar mais variáveis sociais, pois há estudos, como o de loris (2006), que versam sobre o ciclo hidrossocial que estabelece uma relação indissociável entre a sociedade e os recursos hídricos. Esse incremento mitiga a possibilidade de gerar cenários errôneos, maximiza a fidelidade dos resultados obtidos com a realidade objetiva e impulsiona as perspectivas interdisciplinares e multidisciplinares nos estudos socioambientais.

Apesar da larga utilização do conceito de BH, verificou-se que, na maioria dos trabalhos que constam na literatura científica, inexiste a preocupação em indicar o conceito de BH que se adota. Este frequentemente está implícito e é identificado a partir da perspectiva de análise e das caracterizações que os autores desenvolvem. Já os trabalhos técnicos, habitualmente, demonstram os aspectos qualitativos e/ou quantitativos dos conceitos que empregam. Tal fato pode estar 
relacionado à naturalização sofrida pela $\mathrm{BH}$ no âmbito acadêmico, por isso tem sua qualificação omitida.

Com base nas definições expostas, intui-se que tais definições, apesar de distintas e com enfoques diferentes, não se anulam ou são contraditórias, mas se sobrepõem e complementam-se mutuamente. $\mathrm{O}$ uso de uma variação conceitual de $\mathrm{BH}$ deve estar vinculado à perspectiva da pesquisa a ser desenvolvida, afinal a multidimensionalidade de uma BH ainda dificulta a sua apreensão enquanto totalidade, embora haja tentativas para superar esse problema.

É evidente que todas as definições apresentadas estão imersas em contextos históricos e paradigmáticos algumas vezes distintos. Contudo, não foi possível vislumbrar nenhum elemento que contraponha a mesclagem das concepções para gerar uma mais complexa, nem mesmo aquela que parte do princípio de que a BH é um território, como apresentam Torres e Vianna (2008), Wani e Garg (2009) e Gaspari et al. (2013). Nessa linha de pensamento, todas as qualificações podem ser combinadas e aplicadas sob o enfoque sistêmico, o qual integra todas as dimensões conhecidas (naturais e sociais) dos seus objetos de estudo.

A partir das definições do quadro 1, sugere-se que a $\mathrm{BH}$ seja entendida como um sistema aberto, multidimensional e dinâmico, passível de delimitação espacial a partir de critérios sociais, geológicos e geomorfológicos integradamente. Dada a sua multidimensionalidade, pode ser concebida também como um hidroterritório ou território, uma paisagem, um sistema ambiental, um geossistema ou como uma bacia de drenagem conforme a natureza do estudo a ser desenvolvido.

Portanto, a BH, quando envolve intervenções sociais, é uma célula de análise que representa um locus transformado pelas forças de trabalho humano, que é dotada de representações culturais que criam a identidade e o sentimento de pertencimento nos seus habitantes. Estes exercem relações de poder, gestão nesse sistema passível de transformações ambientais e subdivisões hierárquicas para fins de sua compreensão holística e eficiência do seu uso e ocupação.

Cabe frisar que os limites de uma BH frequentemente são os seus divisores de águas, onde surgem as nascentes dos riachos que confluem para um rio principal, o qual drena água, sedimentos clásticos e iônicos, energia e informação para um ponto de saída comum, o exutório, ligado a outro sistema ambiental mais complexo.

\section{Sub-bacia hidrográfica: aspectos qualitativos e quantitativos}

A sub-bacia hidrográfica tem sido outra terminologia atribuída às BHs com o intuito de indicar uma hierarquização de seu sistema de drenagem conforme seu nível de complexidade, quantidade de áreas drenadas, ordens dos rios e relações direta que exerce com o rio principal da rede hidrográfica que a engloba. Morfologicamente, é formado pelo prefixo sub-justaposto ao substantivo bacia, modificado pelo adjetivo hidrográfica. Semanticamente, o primeiro designa algo que está abaixo, é inferior ou menor hierarquicamente, enquanto o segundo designa um sistema espacial multidimensional cujas dimensões hidrogeomorfológicas costumam ser seus atributos mais destacados. Portanto, a sub-bacia hidrográfica é entendida como uma BH menos complexa e tributária de outra rede de drenagem que é a principal.

Apesar de os termos sub-bacia e microbacia hidrográfica estarem incorporados na literatura técnico-científica, eles não possuem a mesma convergência conceitual apresentada para $\mathrm{BH}$ (TEODORO et al., 2007), porque, além das questões demonstradas, há divergências expressivas quanto às suas áreas ideais, às ordens fluviais que seus rios devem ter, à hipótese de as BHs precisarem confluir diretamente ou não para o rio principal, à possibilidade de elas poderem ou não ser uma célula de análise viável para estudos hidrossedimentológicos, assim como uma unidade de 
planejamento ou hidroterritório. Desta maneira, estudar os conceitos postos é fundamental para desnaturalizar e romper as alienações presentes no meio técnico-científico.

Assim, o quadro 2 contém os principais conceitos empregados para designar o que é uma subbacia hidrográfica. Ao analisar tal quadro, verifica-se que os autores não se preocupam mais em discorrer sobre as características geomorfológicas da $\mathrm{BH}$ ou acerca de suas funções ambientais (físico-naturais e sociais), pois entendem que a sub-bacia é uma $\mathrm{BH}$, porém menor, menos complexa e desprovida de propriedades emergentes que um sistema maior detém. Logo, eles focam as distinções qualitativa e quantitativa desta em relação à totalidade do sistema de drenagem.

Quadro 2 - Conceitos de sub-bacias hidrográficas presentes na literatura científica e técnica

\begin{tabular}{|c|c|}
\hline Autor(es) & Conceitos e características de uma sub-bacia hidrográfica \\
\hline $\begin{array}{l}\text { Faustino (1996) } \\
\text { apud Teodoro } \\
(2007)\end{array}$ & São BHs com áreas superiores a $100 \mathrm{~km}^{2}$ e inferiores a $700 \mathrm{~km}^{2}$. \\
\hline Rocha (1997) & $\begin{array}{l}\text { A sub-bacia hidrográfica é a área que drena a água das chuvas por meio de } \\
\text { rios e ravinas para um rio principal que pode desaguar no mar, em um lago } \\
\text { ou em outro rio. Assim, tal sistema tem áreas entre } 20.000 \text { ha a } 300.000 \\
\text { ha, contudo estas variam conforme a sua localização geográfica no país. }\end{array}$ \\
\hline $\begin{array}{l}\text { Vélez, Núñez e } \\
\text { Trujano (2003) }\end{array}$ & É uma BH com tamanho entre 5.000 ha a 50.000 ha. \\
\hline $\begin{array}{l}\text { Gangbazo } \\
(2004)\end{array}$ & Entende como uma $\mathrm{BH}$ que alimenta uma bacia maior. \\
\hline $\begin{array}{l}\text { Teodoro et al. } \\
\text { (2007) }\end{array}$ & $\begin{array}{c}\text { As sub-bacias são áreas de drenagem dos tributários do curso d’água } \\
\text { principal. }\end{array}$ \\
\hline $\begin{array}{l}\text { Guatemala } \\
\text { (2009) }\end{array}$ & $\begin{array}{l}\text { Território drenado por um rio principal de uma } \mathrm{BH} \text { formado por um grupo } \\
\text { de microbacias. }\end{array}$ \\
\hline Gálvez (2011) & $\begin{array}{l}\text { A sub-bacia é um conjunto de microbacias cujas drenagens convergem } \\
\text { para um canal com fluxo flutuante, mas permanente. }\end{array}$ \\
\hline $\begin{array}{l}\text { Machado e } \\
\text { Torres (2012) }\end{array}$ & É a BH de um tributário de um rio principal. \\
\hline
\end{tabular}

Ao observarem-se as definições presentes no quadro 2, nota-se que dois critérios básicos são utilizados para diferenciar a sub-bacia de uma microbacia ou de uma $\mathrm{BH}$.

O primeiro é o critério quantitativo, isto é, os pesquisadores atribuem dimensões espaciais arbitrárias para tal fim. Contudo, percebe-se que tais arbitrações são propostas a partir de exemplos empíricos pontuais, por isso não compreendem todas as sub-bacias que podem fugir aos parâmetros numéricos exigidos e reduzem a sub-bacia ao seu tamanho espacial.

o problema de usar a quantificação para definir uma sub-bacia reside no fato de não haver sequer o consenso sobre o tamanho da supracitada entre os autores, como pode ser visto nos conceitos de Faustino (1996), Rocha (1997) e Vélez, Núñez e Trujano (2003), por exemplo. Tal problema também é observado por outros autores, como Teodoro et al. (2007, p. 138), o qual informa que "[...] as sub-bacias são áreas de drenagem dos tributários do curso d'água principal. Para definir sua área os autores utilizam-se de diferentes unidades de medida".

Atualmente, a quantificação de uma sub-bacia não favorece a aplicação geral do conceito para todas as outras devido à diversidade de $\mathrm{BH}$ e a suas características intrínsecas. Soma-se a isso a dificuldade de entendimento e de comunicação global que o termo designa; desta maneira, cria uma 
insegurança conceitual, o uso indiscriminado do aludido termo e a necessidade de defini-lo sempre que for empregado.

No âmbito do critério qualitativo, os conceitos em apreço mostram-se mais eficientes, pois permitem a maleabilidade nos critérios de definição de uma sub-bacia, possibilitando sua aplicação geral, não obstante os critérios adotados devem pautar-se em características gerais presentes em todas as sub-bacias e não podem criar ambivalências com outras classes hierárquicas.

Ao examinarem-se os conceitos de cunho qualitativo, como os de Gangbazo (2004), Teodoro et al. (2007), Guatemala (2009), Gálvez (2011), Machado e Torres (2012), constata-se que apresentam fragilidades vinculadas às delimitações conceituais, causando ambiguidades ou sobreposições com outros níveis hierárquicos de uma $\mathrm{BH}$.

Assim, o conceito de Gangbazo (2004), que entende a sub-bacia como uma BH que alimenta uma bacia maior, é impreciso porque uma $\mathrm{BH}$ ou uma microbacia também apresentam essa característica, logo isso não se configura como um atributo que a distingue das demais, mas como um elo entre elas.

Já a perspectiva de Teodoro et al. (2007) também apresenta fragilidade e limitações, pois compreende as sub-bacias como áreas de drenagem dos tributários do curso d'água principal. Essa afirmação está parcialmente correta, porque elas, frequentemente, deságuam em um rio principal, mas esquecem que o curso principal de um rio também recebe esporadicamente contribuições de microbacias hidrográficas de primeira e segunda ordens de pequenas dimensões espaciais. Essa condição cria também uma ambivalência conceitual, isto é, uma sub-bacia poderá ser uma microbacia e vice-versa. Deste modo, pensa-se que a conceituação dessa categoria deve ir além do fato de contribuir com o rio principal.

A fragilidade presente na definição de Guatemala (2009) assemelha-se à dos demais, porque concebe a sub-bacia como um território drenado por um rio principal de uma $\mathrm{BH}$ composto por um grupo de microbacias. Nessa afirmação, o autor não considerou que, dependendo da dimensão da $\mathrm{BH}$ analisada e do escopo do estudo, uma sub-bacia pode receber aportes de outras análogas.

Exemplificando o caso anterior, destaca-se a rede de drenagem do rio Japurá, com área de drenagem de $255.700 \mathrm{~km}^{2}$, e o seu rio principal tem cerca $2.816 \mathrm{~km}$. Essa é uma sub-bacia do rio Solimões, que, por sua vez, é uma sub-bacia do rio Amazonas. Com isso, constata-se a natureza do problema citado, logo nem toda sub-bacia recebe contribuições somente de microbacias, tampouco a primeira pode ser entendida como uma pequena bacia, logo as críticas feitas valem principalmente para os conceitos apresentados por Gálvez (2011) e Machado e Torres (2012), por exemplo.

Com base nisso, percebe-se que os conceitos com escopo qualitativo também apresentam limitações consideráveis, contudo oferecem elementos relevantes para o aperfeiçoamento conceitual, realista e flexível. Ademais, nota-se que é imperativa a proposição de uma conceituação e sistematização elaboradas no âmbito da hierarquia das BHs para facilitar a comunicação e o entendimento universal da diferença entre $\mathrm{BH}$, sub-bacia e microbacia.

Segundo Botelho (2009), este fenômeno pode estar vinculado à falta de uma conceituação da $\mathrm{BH}$ e consenso sobre tal termo e sua função; com isso, as definições de sub-bacia e microbacia hidrográficas não são bem definidas por estar subordinadas à de $\mathrm{BH}$.

A partir dos conceitos apresentados pelo quadro 2, verifica-se não ser salutar dimensionar quantitativamente o tamanho de uma sub-bacia devido à variabilidade de sistemas de drenagens presentes na Terra. Contudo, propõe-se que a categoria exposta seja entendida como um fragmento multidimensional do sistema fluvial composto essencialmente por outras sub-bacias e/ou microbacias hidrográficas, que apresentam padrões de drenagem endorreica e são tributárias de uma $\mathrm{BH}$ mais complexa. 


\section{Microbacia hidrográfica: características gerais que compõem o conceito}

Entre os conceitos analisados, o mais controverso é o de microbacia hidrográfica, por conta da variabilidade de definições, atributos utilizados para sua delimitação e pela sua semântica. Contraditoriamente, é também um dos termos mais empregados nos trabalhos acadêmicos nacionais e internacionais recentes, notadamente aqueles que versam sobre unidade de planejamento rural ou urbana, avaliação hidrossedimentar, manejo de $\mathrm{BH}$ e célula de análise para zoneamento ambiental.

O termo microbacia é formado pelo prefixo micro-, denotando o que é muito pequeno ou espaço de um milionésimo $\left(10^{-6}\right)$ no Sistema Internacional de Unidades, acrescido do substantivo bacia, que teve sua conceituação demonstrada nas seções anteriores.

Seu emprego ocorre porque vários autores entendem a microbacia como a menor área possível do ecossistema ou do sistema fluvial que favorece a compreensão de parte das características ecológicas e socioeconômicas de uma BH que é tributária (ATTANASIO, 2004; BERTONI e LOMBARDI NETO, 2008; LIMA, 2008). Portanto, é uma célula de análise propícia para a obtenção de dados e informações detalhadas dos elementos ambientais e socioeconômicos, viabilizando a proposição de planos de manejo e sua gestão territorial.

Quadro 3 - Conceitos de microbacia hidrográfica presentes na literatura científica

\begin{tabular}{|c|c|}
\hline Autor(es) & Conceitos e características de uma microbacia hidrográfica \\
\hline $\begin{array}{l}\text { Vélez, } \\
\text { Núñez e } \\
\text { Trujano } \\
\text { (2003) }\end{array}$ & $\begin{array}{c}\text { É uma BH cuja área é de } 3.000 \text { ha a } 5.000 \text { ha, porém, quando as condições } \\
\text { orográficas permitem, podem ser menores. }\end{array}$ \\
\hline $\begin{array}{l}\text { Attanasio } \\
(2004)\end{array}$ & $\begin{array}{c}\text { A microbacia constitui a manifestação de um sistema ambiental aberto, } \\
\text { podendo ser entendida como uma unidade ecossistêmica da paisagem, em } \\
\text { termos da integração dos ciclos naturais de energia, de nutrientes e da água. } \\
\text { Além disso, a sensibilidade às chuvas intensas (curta duração), as variações de } \\
\text { uso do solo e as alterações qualitativo-quantitativas da água de deflúvios são } \\
\text { detectadas com maior facilidade do que em BHs grandes. }\end{array}$ \\
\hline $\begin{array}{l}\text { Bahamond } \\
\text { es e Gaete } \\
\text { (2002) }\end{array}$ & $\begin{array}{l}\text { São aquelas formadas por redes de drenagem de primeira e segunda ordem, } \\
\qquad \text { com uma área de drenagem que varia de } 1 \text { ha } \\
\qquad \begin{array}{l}100 \text { ha. }\end{array}\end{array}$ \\
\hline $\begin{array}{l}\text { Bertoni e } \\
\text { Lombardi } \\
\text { Neto } \\
(2008)\end{array}$ & $\begin{array}{l}\text { A microbacia hidrográfica é uma unidade básica das atividades sociais, sendo } \\
\text { uma área fisiográfica drenada por um ou mais rios conectados e convergentes, } \\
\text { direta ou indiretamente, para um leito ou espelho de água. É uma unidade ideal } \\
\text { para o planejamento integrado, manejo dos recursos naturais e do ambiente por } \\
\text { ela delimitado. }\end{array}$ \\
\hline $\begin{array}{l}\text { Lima } \\
(2008)\end{array}$ & $\begin{array}{l}\text { A "microbacia" é uma área tão pequena que a sensibilidade às chuvas de alta } \\
\text { intensidade e as diferenças de uso do solo não são suprimidas pelas } \\
\text { características da rede de drenagem. Além disso, a área de uma microbacia } \\
\text { pode variar de pouco menos de } 1 \text { ha até } 40 \text { ha, podendo atingir, em algumas } \\
\text { situações, } 100 \text { ha ou mais. }\end{array}$ \\
\hline $\begin{array}{l}\text { Guatemala } \\
\text { (2009) }\end{array}$ & $\begin{array}{l}\text { É o território cujas águas são drenadas para um curso principal de uma sub- } \\
\text { bacia. Assim, a bacia se divide em sub-bacias que, por sua vez, são } \\
\text { compartimentadas em microbacias hidrográficas. }\end{array}$ \\
\hline $\begin{array}{l}\text { Gálvez } \\
(2011)\end{array}$ & $\begin{array}{l}\text { Uma microbacia hidrográfica é toda área em que sua drenagem converge para } \\
\text { um rio principal de uma sub-bacia, portanto esta é composta por diversas } \\
\text { microbacias. }\end{array}$ \\
\hline
\end{tabular}




\begin{tabular}{|c|c|}
\hline $\begin{array}{c}\text { Machado e } \\
\text { Torres } \\
(2012)\end{array}$ & É a drenagem que conflui em um tributário do rio principal. \\
\hline $\begin{array}{c}\text { Hollanda et } \\
\text { al. (2015) }\end{array}$ & $\begin{array}{c}\text { As microbacias hidrográficas são unidades naturais propícias para o } \\
\text { gerenciamento dos recursos naturais, implementação de políticas públicas } \\
\text { conservacionistas e ambientais, pois contêm processos vinculados ao } \\
\text { escoamento hídrico, a atividades sociais e florestais, com destaque para as } \\
\text { inter-relações e impactos sobre os recursos naturais. }\end{array}$ \\
\hline $\begin{array}{c}\text { Echevarría } \\
\text { e Montoya } \\
(2015)\end{array}$ & $\begin{array}{c}\text { É uma parte da sub-bacia hidrográfica. } \\
\text { FAO (2018) }\end{array}$ \\
$\begin{array}{c}\text { A microbacia é uma área que pode ser planificada mediante a utilização dos } \\
\text { núcleo social que compartilha interesses comuns (água, serviços básicos, } \\
\text { infraestrutura, organização, entre outros). Além disso, acrescenta que, em El } \\
\text { Salvador, uma microbacia não deve ter mais de } 700 \text { ha e conter } 100 \text { famílias } \\
\text { dada as condições do terreno, porém pontua que o tamanho ideal é de 250 ha a } \\
350 \text { ha, nele devem habitar de } 50 \text { a } 70 \text { famílias. }\end{array}$ \\
\hline
\end{tabular}

Entretanto, Botelho e Silva (2004) indicam que há uma certa resistência de uma parcela da comunidade científica em adotar a microbacia como célula de análise, pois há casos em que os pesquisadores optam pelo termo sub-bacia hidrográfica, mesmo que isso incorra em um erro semântico, porque, independentemente de suas dimensões, pressupõe não somente sua inclusão em outra bacia maior, como também seu vínculo com ela no estudo abordado, logo, perante as distinções apresentadas na seção anterior, não é salutar criar uma ambivalência terminológica entre os conceitos analisados.

Adicionalmente, notou-se que, na maioria dos trabalhos consultados, não existe a preocupação em definir o que se entende como microbacia hidrográfica, mas simplesmente é informado que suas BHs com as características que apresentam são microbacias. Deste modo, "o uso dos termos bacia, sub-bacia e microbacia hidrográficas parecem obedecer a uma certa escala espacial, entretanto não há um consenso entre a comunidade científica quanto as suas definições" (MOSCA, 2003 p. 5).

A ausência de um consenso resulta também da dificuldade de enquadrar objetos complexos em uma hierarquização e em definições simplistas. Além disso, houve a naturalização do conceito posto devido à sua vasta utilização e à objetividade exigida nos trabalhos científicos que, esporadicamente, podem subsidiar alienações por não exigirem delimitações claras do que se aborda.

Além disso, detectou-se que não há concordância sobre a dimensão espacial, tamanho do rio principal, as ordens dos rios, a densidade de drenagem ou outro atributo que indique uma delimitação segura de uma microbacia. Tal afirmação pode ser fundamentada a partir dos conceitos apresentados pelo quadro 3, onde é possível ver sugestões de áreas que oscilam de 1 ha a 5.000 ha, por exemplo.

Ao examinarem-se as definições expostas no quadro 3, averígua-se que há uma heterogeneidade conceitual quanto ao objeto discutido. Ademais, constata-se a presença de qualitativos simplistas ou complexos, comumente imprecisos no âmbito conceitual estudado. Em consonância com isso, as conceituações de Vélez, Núñez e Trujano (2003), Gálvez (2011), Machado e Torres (2012) e Echevarría e Montoya (2015) são as mais simples, pois se limitam a informar que a microbacia hidrográfica é uma drenagem integrante de uma sub-bacia, que conflui para um rio principal ou que tem uma determinada área espacial. 
Já as definições de Attanasio (2004), Bertoni e Lombardi Neto (2008), Lima (2008), FAO (2018) e Hollanda et al. (2015) são mais complexas em relação às primeiras por trazer mais elementos na caracterização e discretização de uma microbacia hidrográfica. Contudo, ainda oferecem atributos vagos ou difíceis de ser obtidos, complicando o estudo e o enquadramento do objeto analisado.

A definição de Vélez, Núñez e Trujano (2003) reduz a microbacia a uma área espacial arbitrária, logo aquelas maiores ou menores do que os parâmetros estabelecidos tendem a ser desconsideradas. Já Gálvez (2011) não considera a possibilidade de uma microbacia desaguar em um rio principal de uma $\mathrm{BH}$ sem passar por uma sub-bacia, sendo esta a sua maior limitação conceitual.

Com relação à definição de Machado e Torres (2012), esta cria ambivalências com os outros conceitos tratados e não oferece subsídios para uma delimitação clara do objeto por não ter elementos que a distingam das demais categorias de BH. Por fim, Echevarría e Montoya (2015) reduzem a microbacia a um elemento de uma sub-bacia, o que nem sempre é uma realidade, pelos motivos já indicados nas seções anteriores. Portanto, os autores mencionados escolheram aspectos controversos como características principais para qualificar e delimitar uma microbacia das demais classes.

Não obstante as abordagens mais complexas do termo tratado também apresentarem imprecisões, o conceito de Attanasio (2004), incialmente, é restrito porque emprega características que as demais categorias de BH têm. Tanto o autor citado quanto Lima (2008) não indicam quais as técnicas e os intervalos dos parâmetros adequados para mensurar a sensibilidade de uma $\mathrm{BH}$ às chuvas intensas. Assim, quais os graus e as variações do uso do solo e da água de deflúvios devem ser considerados para identificar uma microbacia hidrográfica? A ausência disso demonstra as imprecisões dos conceitos adotados, embora tenham mais elementos qualitativos que os demais examinados.

Bahamondes e Gaete (2002) restringem-se a qualificar uma microbacia a partir das ordens dos canais fluviais da rede hidrográfica e de sua área espacial. Contudo, esses atributos não são substanciais para ser aplicados em todas as BHs da Terra, pois, dependendo da escala de mapeamento da rede hidrográfica, um rio de primeira ordem pode ser um sulco erosivo efêmero, enquanto um rio de segunda ordem pode ser um pequeno riacho sem expressividade espacial ou mesmo um grande rio cuja área de drenagem supera facilmente 100 ha. Casos dessa natureza geralmente ocorrem em $\mathrm{BH}$ com padrões de drenagem em treliças ou paralelos. Desta maneira, $\mathrm{o}$ conceito peca por não poder ser aplicado a todas as microbacias.

A definição dada por Bertoni e Lombardi Neto (2008) está mais alinhada com o conceito de BH do que com o de microbacia. Ademais, trata mais das funções de uma determinada categoria de $\mathrm{BH}$ do que seus atributos para discretizá-las das demais. O entendimento de Guatemala (2009) e Gálvez (2011) reduz a microbacia a um mero tributário de uma sub-bacia, menosprezando a possibilidade de a referida ter uma elevada área espacial ou mesmo ser uma sub-bacia de outra $\mathrm{BH}$.

O entendimento da FAO (2018) também apresenta fragilidades dada a sua falta de precisão, afinal muitas sub-bacias podem ser planificadas com recursos locais, assim como permitem que um determinado número de famílias seja abordado como um núcleo social que compartilha interesses comuns. As áreas espaciais e o número de famílias que, em tese, devem habitá-las são relativos e arbitrários, pois não são demonstrados os critérios para tal indicação.

Por fim, o entendimento de Hollanda et al. (2015) também não auxilia robustamente na delimitação conceitual de uma microbacia, pois ampara-se em aspetos igualmente presentes nas outras categorias hierárquicas de $\mathrm{BH}$ como, por exemplo, a possibilidade de gerenciar recursos naturais, a implementação de políticas conservacionistas. 
Portanto, nota-se que o conceito em apreço é impreciso, pois suas qualidades variam conforme a sua aplicação, dificultando a sua compreensão universal e as comparações entre trabalhos que o utilizam. Os autores citados no quadro 3 tentaram empregar características qualitativas e quantitativas para diferenciar microbacia de sub-bacia e $\mathrm{BH}$, porém nota-se que a problemática ainda se encontra sem solução, pois os conceitos apresentados demonstram falhas em suas qualificações e quantificações decorrentes do caráter complexo da célula analisada.

Além disso, assim como ocorre nas adjetivações das categorias postas, ainda há detalhes sem consenso como a área de uma unidade de planejamento. Afinal, o critério para sua delimitação é político-administrativo. Outra questão é o fato de restringir um determinado plano econômico ou de desenvolvimento a um espaço físico pequeno e desconexo do seu entorno, pois as atividades socioeconômicas e culturais estendem-se para dimensões maiores. Com efeito, o planejamento e a gestão de uma microbacia também devem prezar pela matriz onde está inserida.

Logo, a partir dos antecedentes, constata-se que a microbacia hidrográfica apresenta partes das qualidades de uma $\mathrm{BH}$, ou seja, é um hidroterritório, uma unidade de paisagem, uma unidade de planejamento, um ecossistema, assim como é um sistema ambiental aberto, não obstante apresenta especificidades próprias por ser menor espacialmente, por conter rios menos caudalosos e por ser menos complexa que a primeira, não contendo, assim, as propriedades emergentes inerentes a uma $\mathrm{BH}$ hierarquicamente maior.

Sendo assim, concebe-se a microbacia hidrográfica como a menor categoria hierárquica de uma $\mathrm{BH}$, que habitualmente é representada por drenagens de primeira e segunda ordens (podendo abranger um rio de terceira ordem, caso um ou mais de seus antecedentes sejam canais efêmeros) que confluem para uma sub-bacia ou para a $\mathrm{BH}$ mais complexa do sistema fluvial. Ademais, trata-se de uma unidade multidimensional, é formada por um conjunto de elementos naturais, socioeconômicos e culturais que estabelecem inter-relações dinâmicas e funcionais por meio dos fluxos de energia, informações e ciclagem de matéria.

\section{Considerações finais}

Apesar de a temática de hierarquização de $\mathrm{BH}$ ser muito utilizada, não foi encontrada, até o momento, nenhuma metodologia ou esboço teórico que apresente uma tipologia robusta sobre a hierarquização de $\mathrm{BH}$, sub-bacia e microbacia hidrográfica e cujas conceituações não detenham as limitações discorridas, porém detectou-se que há esforços para tal feito, mas estes ainda são ineficientes para a resolução do problema globalmente.

Atestou-se que os conceitos abordados passaram por adaptações ao longo do tempo, para ser ajustados aos interesses e às escalas dos diversos trabalhos técnico-científicos que os criaram e aplicaram. Em razão disso, tais trabalhos apresentam diversas definições.

Notou-se que o atual sistema hierárquico de $\mathrm{BH}$, formado por três categorias $(\mathrm{BH}$, sub-bacia e microbacia), é permeado por problemas relacionados à imprecisão de seus conceitos, por fragmentar um sistema fluvial complexo somente em três segmentos.

No que tange às limitações conceituais, estas se iniciam no âmbito semântico dos termos de sub-bacia e microbacia. No primeiro caso, o prefixo sub- designa algo que está abaixo, é inferior ou se aproxima de algo (FERREIRA, 2014), portanto a sub-bacia é uma categoria inferior multidimensionalmente em relação à $\mathrm{BH}$ da qual é tributária. Geralmente, o sub é utilizado em uma lógica dualística, tendo o sobre (superioridade e acima de) como o seu prefixo oposto.

Contudo, há a possibilidade da utilização do prefixo mes(o)- (meio, ponto médio e entre os extremos), tendo em vista que habitualmente há uma categoria mediana entre oposições. 
Correntemente, na prática, essa dimensão é representada pela sub-bacia, porque o sistema hierárquico de $\mathrm{BH}$ em vigor considera apenas três categorias. Assim, o prefixo sub poderá indicar que tal bacia é a de menor nível de um sistema, substituindo a microbacia.

Já o termo microbacia também apresenta fragilidades, pois, segundo Ferreira (2014), micro significa muito pequeno ou, de acordo com o Sistema Internacional de Unidades, representa objetos com dimensões de um milionésimo $\left(10^{-6}\right)$, neste caso não condizendo com tamanhos de uma $\mathrm{BH}$, mesmo que pequena.

Com isso, observa-se que o sistema hierárquico de $\mathrm{BH}$ em vigor aglutinou classes oriundas de classificações semânticas distintas, isto é, criou-se a sub-bacia a partir do prefixo sub, tendo o sobre e o mes(o) como ordens afins. Já no caso da microbacia, aplicou-se o micro, que parte de uma grandeza métrica ou de níveis como muito grande, grande, médio, pequeno e muito pequeno para diferenciar as $\mathrm{BH}$ por tamanho, complexidade e função.

A área espacial e a ordem fluvial oferecem limitações para a diferenciação de sub-bacia e microbacia, pois a maioria dos trabalhos consultados consideram como microbacias as redes que contêm rios até de terceira ordem, conforme a metodologia do Strahler (1957). Não obstante há subbacias cuja rede de drenagem é composta por rios de terceira ordem também. Deste modo, o emprego de conceitos balizados puramente em aspectos quantitativos não se mostrou eficiente em razão da sua arbitrariedade e da ausência de parâmetros universais e por possibilitar a ocorrência de ambivalências conceituais.

Acredita-se que tal panorama somente poderá ser revertido a partir do desenvolvimento de mais estudos que possam indicar intervalos espaciais gerais para as classes hierárquicas tratadas. Além disso, notou-se que definições baseadas em aspectos qualitativos são mais adequadas para delimitar globalmente as categorias analisadas, pois são flexíveis perante a complexidade e diversidade de $\mathrm{BH}$ terrestres.

Observou-se que há uma banalização no uso das categorias hierárquicas de uma BH, especialmente o de microbacia hidrográfica, mas grande parte dos trabalhos acadêmicos estudados não explicam o motivo pelo qual usam o termo microbacia hidrográfica em vez de sub-bacia ou BH. Soma-se a isso a ausência de explicações do que os pesquisadores entendem ser uma microbacia, logo a delimitação dessa classe está relacionada a sua função ambiental, à subjetividade dos pesquisadores e à natureza do objeto tratado.

De todas as categorias, a BH é a que apresenta maior nível de complexidade e mais definições, afinal é a categoria que permite um maior nível de abstração. A sub-bacia possui definições com falhas nas suas delimitações, contudo elas permitem uma compreensão superficial das suas características gerais sem complicações, o que não ocorre à microbacia.

Apesar da larga utilização do conceito de microbacia hidrográfica, detectou-se que não há um consenso ou uma delimitação conceitual uniforme que facilite um entendimento global ou que permita a realização de comparações de obras que utilizam tal conceito, porque sua qualificação e/ou quantificação têm sido vinculadas à natureza empírica e subjetiva de cada contexto em que é empregado.

Cabe frisar que, embora essa célula de análise seja multidimensional, à medida que sua complexidade e tamanho são reduzidos, ela tende a perder dimensões; por exemplo, se um sulco erosivo for entendido como uma microbacia, aquele não pode ser entendido como uma unidade de planejamento e gestão, por conta do seu tamanho e menor complexidade. 


\section{Agradecimentos}

Agradecemos a Fundação Cearense de Apoio ao Desenvolvimento Científico e Tecnológico (FUNCAP) e a Coordenação de Aperfeiçoamento de Pessoal de Nível Superior (CAPES), respectivamente pelas bolsas de doutorado e doutorado sanduíche em Cabo Verde por meio do Programa Associação das Universidades de Língua Portuguesa (AULP) 88887.198996/2018-00 para o primeiro autor. Obrigado a Alistair Douglas Simpson e Francisco Mariano Neto, respectivamente, pelas contribuições nas traduções do resumo e correção ortográfica, morfossintática e semântica do artigo.

\section{Referências}

ANA, Agência Nacional de Águas. (2018) Região hidrográfica Atlântico Nordeste Oriental. Disponível em: <http://www2.ana.gov.br/Paginas/portais/bacias/AtlanticoNordesteOriental.aspx>. Acessado em: 23 abril 2018.

ARAÚJO, J. C. de. (2003) Assoreamento em reservatório do semi-árido: modelagem e validação. Revista Brasileiro de Recursos Hídricos. v.8, n. 2, p. 39-56.

ATTANASIO, C. M. (2004) Planos de manejo integrado de microbacias hidrográficas com uso agrícola: uma abordagem hidrológica na busca da sustentabilidade. 2004. 192f. Tese (Doutorado em Recursos Florestais) - Escola Superior de Agricultura Luiz de Queiroz, Universidade de São Paulo.

BAHAMONDES, R.; GAETE, N. (2002) Manejo de cuencas hidrográficas. Serie Actas: Instituto de Investigaciones Agropecuarias. Temuco-Chile: P. Impreta, p. 1-14.

BERTONI, J.; NETO LOMBARDI, F. (2008) Conservação do Solo. 6.ed. São Paulo: Ícone, 354p.

BOTELHO, R. G. M.; SILVA, A. S. da. (2004) Bacia hidrográfica e qualidade ambiental. In: VITTE, A. C.; GUERRA, A. J. T. (Orgs.). Reflexões sobre a geografia física no Brasil. Rio de Janeiro: Bertrand Brasil, p.153-192.

BOTELHO, R. G. M. (2009) Planejamento ambiental em microbacia hidrográfica. In: GUERRA, A. J. T.; SILVA, A. S. da; BOTELHO, R. G. M. (Org.). Erosão e Conservação dos Solos - conceitos, temas e aplicações. 4 ed. Rio de Janeiro: Bertrand Brasil, p. 269-300.

BRASIL. Lei N 9.433, de 8 de jan. de 1997. (1997) Dispõe sobre a instituição da Política Nacional de Recursos Hídricos, cria o Sistema Nacional de Gerenciamento de Recursos Hídricos, regulamenta o inciso XIX do art. 21 da Constituição Federal, e altera o art. $1^{\circ}$ da Lei n 8.001, de 13 de março de 1990, que modificou a Lei no 7.990, de 28 de dezembro de 1989. Diário Oficial da República Federativa do Brasil, Brasília, DF, 8 de jan. 1997. Disponível em: <http://www.planalto.gov.br/ccivil_03/LEIS//9433.htm>. Acessado em: 14 abril. 2018.

CHORLEY, R. J. (1962) Geomorphology and general systems theory. Geological survey professional paper 500 b. Washington: United States Government Printing Office, 11p.

CHRISTOFOLETTI, A. (1979) Análise de Sistemas em Geografia. São Paulo: HUCITEC: Ed. da Universidade de São Paulo, 106p.

CHRISTOFOLETTI, A. (1980) Geomorfologia. 2.ed. São Paulo: Edgar Blucher, p. 65- 121.

CHRISTOFOLETTI, A. (1981) Geomorfologia fluvial. São Paulo: Edgard Blucher, 313p.

CHRISTOFOLETTI, A. (1999) Modelagem de sistemas ambientais. São Paulo: Editora Blucher, 236p.

COELHO NETTO, A. L. (2009) Hidrologia de Encostas na Interface com a Geomorfologia. In: GUERRA, A. J. T.; CUNHA, S. B. da (Org.). Geomorfologia: uma atualização de base e conceitos. Ed. 9. Rio de Janeiro: Bertrand Brasil, p. 93-148. 
CUNHA, S. B. da. (2007) Geomorfologia fluvial. In: CUNHA, S. B. da; GUERRA, A. J. T. (Orgs.). Geomorfologia: uma atualização de bases e conceitos. 7. ed. Rio de Janeiro: Bertrand Brasil, p. $211-$ 252.

CUNHA, T. B. et al. (2012) Mapeamento e tipologia dos conflitos pela gestão e controle das águas no Estado da Paraíba. Boletim de Geografia (UEM), v. 30, p. 31-43.

ECHEVARRÍA, L. H.; MONTOYA, R. O. (2015) Disponibilidade del recurso hídrico en la microcuenca del río Bermúdez, Región Central de Costa Rica. Observatorio Medioambiental. v. 18, p. 165-181.

FAUSTINO, J. (1996) Planificación y gestión de manejo de cuencas. Turrialba: CATIE, 90p.

FAO. Organização das Nações Unidas para Alimentação e Agricultura. (2018) Nota técnica N 1 - La microcuenca como ámbito de planificación de los recursos naturales. Disponível em:< file://C:/Users/raulc/Desktop/BH/Microcuenca\%20FAO.pdf>. Acessado em 28 de mar. de 2018.

FERREIRA, A. B. de H. (2014) Dicionário Aurélio de Língua Portuguesa. 5. ed. Curitiba: Ed. Positivo, $2272 p$

GANGBAZO, G. (2004) Gestion intégrée de l'eua par bassin versant: concepts et application. QuebecCanadá: Environnement Quebec, 46p.

GUATEMALA, Comisión Nacional de Microcuencas (Proyecto Tacaná). (2009) Guia para la Elaboración de Planes de Manejo de Microcuencas. San Marcos- Guatemala: Unión Internacional para la Conservación de la Naturaleza, Oficina Regional para Mesoamérica, 66p.

GÁLVEZ, J. J. O. (2011) Cartilha Técnica: águas subterrâneas - acuíferos. Lima- Perú: Sociedad Geográfica de Lima, 43p.

GASPARI, F. J. et al. (2013) Elementos metodológicos para el manejo de cuencas hidrográficas. La Plata: Universidad Nacional de la Plata, 188p.

GUERRA, A. T.; GUERRA, A. J. T. (2008) Dicionário geológico-geomorfológico. 6.ed. Rio de Janeiro: Bertrand Brasil, 652p.

HOLLANDA, M. P. et al. (2015) Avaliação do TOPMODEL na estimativa do escoamento superficial em microbacia hidrográfica em diferentes usos. Revista Brasileira de Engenharia Agrícola e Ambiental, v. 19, n.5, p. 489-496.

HORTON, R. E. (1945) Erosional development of streams and their drainage basins: a hydrophysical approach to quantitative morphology. Geol Soe. Am. Bull., v.56, n.3, p. 275-370.

IORIS, A. A. R. (2006) Passado e presente da política de gestão dos recursos hídricos no Brasil. Finisterra, v.41, n. 82, p. 87-99.

KARMANN, I. (2009) Água: ciclo e ação geológica. In: TEIXEIRA, W. et al. Decifrando a Terra. 2. ed. São Paulo: Companhia Editora Nacional, p. 186-209.

LIMA, W. de P. (2008) Hidrologia florestal aplicada ao manejo de bacias hidrográficas. 2. ed. São Paulo: Universidade de São Paulo, 253p.

MACHADO, P. J. de O.; TORRES, F. T. P. (2012) Introdução à hidrogeografia. São Paulo: Cengage Learning, 178p.

MAIA, R. P. (2006) Origem e evolução natural do Baixo Jaguaribe - Ceará. In: SILVA, J. B. da; DANTAS, E. W. C.; ZANELLA, M. E.; MEIRELES, A. J. de A. (Orgs.) Litoral e sertão: natureza e sociedade no Nordeste brasileiro. Fortaleza: Expressão Gráfica, 251-266p.

MAIA, R. P.; BEZERRA, F.H.R. (2011) Neotectônica, geomorfologia e sistemas fluviais: uma análise preliminar do contexto Nordestino. Revista Brasileira de Geomorfologia. v.12, n.3, p.37-46.

MARTINS, R. H. (2013) Hidroterritórios: os territórios da água no Córrego Sossego - Itarana/ ES. 2013. 80f. Dissertação (Mestrado em Geografia) - Centro de Ciências Humanas e Naturais, Universidade Federal do Espírito Santo. 
MELO, E. T. (2009) A microbacia hidrográfica como unidade de planejamento ambiental: uma proposta para o semi-árido do Brasil. In: SAMPAIO, L. F.; SOUSA NETO, M. F. de; LIMA, A. E. F. et al. (Orgs.). Diálogos sobre sociedade, natureza e desenvolvimento. Fortaleza: Edições UFC, p. 133-144. MOLLE, F. (2009) River-basin planning and management: the social life of a concept. Geoforum, v. 40, p. 484-494.

MOSCA, A. A. de O. (2003) Caracterização hidrológica de duas microbacias visando a identificação de indicadores hidrológicos para o monitoramento ambiental do manejo de florestas plantas. 2003. $88 f$. Dissertação (Mestrado em recursos Florestais) - Escola Superior de Agricultura Luiz de Queiroz, Universidade de São Paulo.

NAQVI, H. R. et al. (2015) Soil erosion planning using sediment yield index method in the Nun Nadi watershed, India. International Soil and Water Conservation Research, v. 3, p. 86-96.

NOVO, E. M. L. de M. (2008) Ambientes fluviais. In: FLORENZANO, T. G. (Org.). Geomorfologia: conceitos e tecnologias atuais. São Paulo: Oficina de Textos, p. 219-247.

PUMO, D. et al. (2014) Annual flow duration curves assessment in ephemeral small basins. Journal of Hydrology, n. 519, p. 258-270.

QUEIROZ, P. H. B. de. et al. (2018) Caracterização multitemporal de barras e ilhas fluviais no baixo curso do rio Jaguaribe, Ceará-Brasil. Revista Brasileira de Geomorfologia, v. 19, n. 1, p. 169-188.

ROCHA, J. S. M. da. (1997) Manual de projetos ambientais. Brasília: MMA, 446 p.

SANJAUME, M. S.; VILLANUEVA, R. J. B. (1996) Teoría y método em geografía física. España: Editorial Sintesis, p. 67-89.

SANTOS, R.F. (2004) Planejamento ambiental: teoria e prática. São Paulo: Oficina de Textos,184p.

SOUZA, M. J. N. de; SANTOS, J. O.; OLIVEIRA, V. P. V. de. (2012) Sistemas ambientais e capacidade de suporte na bacia hidrográfica do rio Curu - Ceará. Revista Continentes (UFRRJ), v. 1, p.119-143.

SOUZA, A. O.; PEREZ FILHO, A. (2016) Mudanças na dinâmica fluvial da bacia hidrográfica do ribeirão Araquá: eventos tectônicos e climáticos no Quaternário. Geousp - Espaço e Tempo (Online), v. 20, n. 3, p. 636-656.

STRAHLER, A. N. (1957) Quantitative analysis of watershed geomorphology. New Halen: Transactions: American Geophysical Union, v. 38, p. 913-920.

STRAHLER, A. N. (1979) Las aguas de escorrentía y de saturación. In: STRAHLER, A. N. Geografía física. Barcelona: Ediciones Omega S. A. p.449-475.

SUGUIO, K. Dicionário de geologia sedimentar e áreas afins. (1998) Rio de Janeiro: Bertrand Brasil, 1.222p.

VÉLEZ, A. S. S.; NúÑEZ, R. M. G.; TRUJANO, A. P. (2003) La cuenca hidrográfica: unidad básica de planeación y manejo de recursos naturales. México: Secrataria de Medio Ambiente y Recursos Naturalez, 49p.

TEODORO, V. L. I. et al. (2007) O conceito de bacia hidrográfica e a importância da caracterização morfométrica para o entendimento da dinâmica ambiental local. Revista UNIARA, v. 20, p. 137-156.

THORNBRUGH, D. J. et al. (2018) Mapping watershed integrity for the conterminous United States. Ecological Indicators, v. 85, p. 1133-1148.

TORRES, A. T. G.; VIANNA, P. C. G. (2008) Hidroterritórios: a influência dos recursos hídricos nos territórios do semi-árido nordestino. Terra Livre, v. 2, p. 145-162.

TUNDISI, J. G. (2008) Recursos Hídricos no Futuro: problemas e soluções. Estudos Avançados, v. 22, p. 7-16.

WANI. S. P.; GARG, K. K. (2009) Watershed management concept and principles. Best-bet Options for Integrated Watershed Management. ICRISAT Patancheru, Andhra Pradesh, India, p.1-11. 